\title{
The main growth strategies of telecommunication operators in the segment of SOHOs
}

\author{
Armand Faganel \\ University of Primorska, Koper, Slovenia \\ https://orcid.org/0000-0002-3618-4986 \\ Igor Jecl \\ Sava turizem, d.d., Ljubljana, Slovenia
}

\section{Arne Baruca}

Texas A\&M University, San Antonio, United States of America

\begin{abstract}
Digital transformation causes a comprehensive change of the company through the use or renewal of information and communication technologies with the aim of greater productivity, growth and competitiveness of the company. Digitization offers new business opportunities to companies, optimization of work processes and operations, more efficient operations, higher productivity, new ways of designing and operating business models, encouraging innovation and development, and new ways of promoting, communicating and connecting companies. Telecom operators are confronted with a choice between remaining a traditional telecommunications operator providing $\mathrm{SOHO}$ (small office/home office) businesses basic infrastructure services or switching to digital transformation. This study confirms that the SOHO market segment in the field of basic infrastructure of telecommunications services is saturated, that there is a potential for operators to offer additional services, and that customer loyalty is not related to the amount of implemented business solutions. Operators can thus build a business partnership in terms of mutual development and creating growth for all stakeholders in the process. The main guidelines of growth present a great opportunity for operators, arising from the challenges of $\mathrm{SOHO}$ businesses to switch to the process of digital transformation. Therefore, operators have to be prepared; the main guidelines of growth are conditioned by adjusting their strategic goals, redefining business processes, upgrading technology, raising the level of business relationship and developing a partner ecosystem.
\end{abstract}

\section{Keywords}

telecommunications, digital transformation, growth strategies, saturation, market, services, $\mathrm{SOHO}$, optimization

\section{Introduction}

Vrana and Singh (2021) explain that the phenomenon of "digitization is around us since the third revolution. Over the last decade or so, digitalization has also been observed to a point where it is now ready for digital transformation, in sync with the fourth industrial revolution. The intermediary step of digitalization overlaps the third and fourth revolution and can sometimes be confusing". Digital transformation will be crucial for growth in business operations in the global market in the future (Fabre \& Skorupa, 2020). But what and how to do it poses a major challenge for leaders in the telecommunications (TC) industry. Fabre and Skorupa (2020) state that digital revolution is a revolution in consumer behavior and business opportunities, not technology. The dramatic rise of smart and autonomous devices is leading to radical shifts in business practices and 
individual behavior. The forecast for the coming years predicts the continuation of a digital future in a world driven by algorithms and smart devices (Janeš, Biloslavo, \& Faganel, 2017). Businesses and individuals face the urgent need to define and develop harmonious relationships between people and devices. Relationships between devices and people are becoming increasingly competitive as smart devices gain more ability to perform more and more everyday activities.

So-called 'smartness' is now present virtually everywhere in the work environment and its consequences are difficult for decision-makers and individuals in companies to predict. Changes are coming fast. Google and Facebook compete and invest billions of dollars in providing online infrastructure through unmanned solar devices drones and helium balloons. In this way, they will provide access to the Internet to the four billion people who are still without it at the moment (Simonite, 2015).

Katz, Jung and Callorda (2020, p.1) study confirms that a "reliable TC infrastructure and a high level of digitization is crucial to keep the economy running under pandemic conditions". The explosion of global pandemic situation in 2020 and 2021 exposed "the fact that telecommunications are both a lifeline and an enabler for modern societies" (European telecommunications network operators association [ETNO], 2021, p.4). While the TC operators' revenues continue to decline worldwide for over a decade (ETNO, 2021, p.4). In the Slovenian telecommunications sector, where as many as 152 operators are registered (Agencija za komunikacijska omrežja in storitve Republike Slovenije [AKOS], 2021), a relative saturation of traditional fixed and mobile telephony services is being faced. Telekom Slovenia (2021) states in its report: " $[\ldots]$ a further drop in revenues from basic telecommunication services is expected on the Slovenian telecommunications market, which is developed and already in the phase of saturation (including systems integration and cloud services." These developments lead TC operators to thoroughly rethink their strategies.

\section{Literature review}

Total revenues from traditional basic infrastructure services and related ancillary services and standard and dedicated cloud business solutions are expected to increase (Bailey, 2015). Literature predicts global revenue growth in the micro enterprise segment (Garcia, 2021; Mouelhi \&
Ghazali, 2021; Rand \& Tarp, 2020; Sahoo \& Swain, 2020). These revenues are mostly related to the growth of cloud services and business solutions.

The TC industry evolved significantly from fixed to mobile substitution (FMS) to fixed mobile convergence (FMC) and finally to over-the-top (OTT) services because of the immense growth in data usage (Chen, 2019). OTT services could be seen as complementary, but they can also substitute the traditional TC services offered by the licensed operators (Sridhar, 2019). OTT service offers the content which is a part of basic TC subscriptions without the added features that are usually supplied by TC operators (across an IP network or via a company's existing IP-VPN (Internet Protocol Virtual Private Network) from another provider, instead of owing the access network). The growing OTT business impacted heavily on traditional TC businesses such as short message and voice services, and the fall of revenues from TC operators indicates that the channeling trend is becoming quite obvious. Due to the booming competition in the field of distribution of interests between contents and channels, OTT service providers and TC operators engage in an aggressive cooperation game and competition (Wang, 2021).

Farooq and Raju's (2019) study confirmed that TC companies' revenue is decreasing but it also brings huge opportunities to them. TC companies can benefit from the change of their customer preferences in a way to understand their needs, and to produce and sell Internet and digital value-added products and services in parallel with traditional TC services.

Krüssel and Göbel (2019) suggest that TC operators could enlarge their actual services and start offering services OTT companies serve. Authors believe it would minimize the existing gap between the end user and company, and to do this, TC operators' infrastructure is of huge importance. Their opinion is that OTT companies and resellers will disappear.

Ganuza and Viecens (2014) assert that the technology that permitted the bundling of services helped TC operators to enter the content market; so today online TV could represent their departure gate in case they wouldn't exhibit novel strategies to stay in the quickly evolving market.

According to Farooq and Raju (2019), TC operators could focus on services to provide customer usage trends and other analysis to their clients - SOHO (small office/home office) 
companies to help them develop their own marketing strategies, as they possess enormous amount of data that represents a valuable asset. There are diverse strategies that TC operators could develop, such as (Farooq \& Raju, 2019; Sujata et al., 2015): blocking OTT, bundling with OTT, partnering with OTT, developing their own services, filling the gap in the market, customized low-price OTT services, specialized OTT bundles, selling apps using customer information, or looking for other revenue streams.

Data analytics is considered by TC operators a viable strategy, and they continue to develop this direction, to further build the loyalty of their customers from micro and SME (small and medium-sized enterprises) companies. In this pursuit, they met several dilemmas in their search of the right use cases, and finding the right technology solutions among conundrum of available choices (Arthur D. Little, 2018). Wiersma and Nijboer (2021) predict global expectations of heavy growth in data usage, because of the introduction of 5G technology. It could be said that $5 \mathrm{G}$ systems will bring a revolution to the reliability, speed, and capacity of TC networks of today.

There is a plethora of studies in the last few years' literature dealing with digital transformation consequences of small companies' business models and strategies in different countries (e.g. Kim, 2021; Matarazzo, Penco, Profumo, \& Quaglia, 2021; Pelletier \& Cloutier, 2019; Peter, Kraft, \& Lindeque, 2020), different industries (e.g. Dutta, Kumar, Sindhwani, \& Singh, 2020; Faganel, \& Costantini, 2020; Garzoni, De Turi, Secundo, \& Del Vecchio, 2020; Gošnik \& Stubelj, 2021; Novak \& Janeš, 2019), and Covid-19 influences (e.g. Mandviwalla, \& Flanagan, 2021; Papadopoulos, Baltas, \& Balta, 2020; Priyono, Moin, \& Putri 2020).

Kääriäinen et al. (2021) argue that small companies are having difficulties with digital transformation due to their limited resources and know-how. Klein \& Todesco $(2021,117)$ agree; they say "scarcity of financial resources and lack of specialized knowledge", together with the current Covid-19 pandemics especially struck small companies. Bouwman, Nikou and de Reuvera's (2019) study on 321 European small companies proves that they can undertake different routes to improve their performance when digital transformation is changing their business model.

Ramnath Babu and Sivanesan (2020, 1123) research on factors influencing the choice decision of mobile network operators showed that small companies mostly value "service provider's brand trust and integrity can be interpreted as a fundamental for a value that is being created and developed by direct experience of consumers". They also gave "higher importance to the intangible values such as reputation as leader in price, service and class of customers as these elements link the overall perception of reputation to identity, image and brand" (Ramnath Babu \& Sivanesan, 2020, 1123).

Dasanayaka, Al Serhan, Glambosky and Gleason (2020) analyzed factors which affect the business-to-business relationship between national TC vendors and operators. They found out that TC vendors and operators value commitment, trust, communication and adaptability. Tarvainen (2020) analyzed European telecommunication operators' strategies distinct strategic positioning and concludes that the majority of them noticed the opportunity in developing service offers for small companies.

Curwen and Whalley (2004) already announced key strategic concepts in the TC industry, which included convergence and specialization, protecting core markets, and managing industrial transition. These concepts evolved and developed in different directions, stimulated by changes in the industry and environment.

Hushyar, Braun and Eslambolchi (2021) confirm that an extreme transformation in the telecommunication industry is currently in progress, from a traditional Communication Service Provider (CSP) to a Digital Service Provider (DSP) which implies a total redesign of connectivity services to digital services; "redefinition of the measurements to customercentric QoE for all digital and connectivity services; the Best-in-Industry processes and practices to ensure a sustainable network performance at a competitively operational efficiency; a Service-over-IP (SoIP) platform to enable the introduction of unified new services with a time-to-market urgency; the regulatory arrangement for content purification, to liberalize CSPs to become DSPs; an architecture for data mining and analytics; and a migration plan from a CSP to a DSP status". This means that the strategies of TC operators have to be very flexible and under constant change.

\section{Analysis}

It is interesting to know whether operators face saturation in their core business (core infrastructure 
services) in the SOHO segment, whether there is a possibility for TC companies to expand their activities to other ICT areas, such as business solutions, where there is still a lot of space left in the SOHO market, and whether companies, by marketing business solutions, reduce the probability of terminating contracts or relationships in basic activities, which will be reflected in the loyalty of business users to the operator.

The survey was conducted in an application developed by Valicon company. Valicon's Assisted Interviewing (AI) software covers all computer-assisted data collection processes and enables computer-assisted survey data collection online (CAWI - computer assisted web interviewing. Respondents have the opportunity to respond when they have the time, which is reflected in a higher response rate. This is especially important for the business segment, where the target group often does not have time to respond to the survey questionnaire at the time the research agency contacts them, which is the case for telephone or field research. Valicon's system exports data in a format suitable for use in the IBM SPSS software tool. The questionnaire on Telco panel comprises 77 survey questions. There are 9 demographic questions: 5 about the respondent and 4 about his/her company and industry; 17 questions about the actual use of TC services and operators. Then there are 51 questions on satisfaction with internet and mobile providers, internet and mobile services, intentions to change the operator, use and intentions to adopt additional services. Out of these, 13 questions use 6-point Likert scale, from 1 -very unsatisfied to 6-very satisfied, or 1-very unlikely to 6-very likely. The survey is standardized and carried out continuously in the panel. The questionnaire was tested and the indicators were checked by experts at Valicon in collaboration with their clients. The IBM SPSS, version 24.0 was used for data analysis.

\subsection{Collecting data}

The survey was conducted on the JazVem web panel (www.jazvem.si) of Internet users in Slovenia, managed by Valicon. It includes 25,000 members, including business users. At the time of the survey, a number of 920 company representatives met the conditions for participation (self-employed, small company owner, director or leading position in a company). Invitations were sent to their e-mail addresses. An additional reminder was sent to selected members who did not respond to the invitation within seven and an additional seven days. The final response rate was $45 \%$ (417 companies).

\subsection{Hypotheses}

Hypothesis 1: The market of basic infrastructure telecommunications services in the $\mathrm{SOHO}$ segment in Slovenia is saturated, so there is no more room for growth.

The level of saturation represents a point in the market when it is not possible to acquire new users or services due to reduced demand, increased competition or higher supply compared to demand. The equipment of companies in the $\mathrm{SOHO}$ segment is on the verge of saturation in terms of the use of basic TC services. All companies use mobile telephony for business purposes and the vast majority of companies use a fixed connection to the Internet for business purposes. The needs of companies differ by activity, so it is assumed that in certain segments of companies (companies whose activities are related to field work) traditional basic TC services such as fixed telephony will no longer be able to reach a large majority or penetration will not be $100 \%$.

The realistic saturation threshold is slightly lower and will be determined based on additional cross-analysis by size and nature of the company. If there are statistically significant differences in use by individual groups of companies, it means that the saturation threshold is lower than $100 \%$ and that there is saturation on the market by individual activity or industry. The statistical characteristic will be checked with P-value statistics, which are calculated using the chi-square test. The sample size is taken into account when calculating the P-value. The selected level of risk will be $10 \%$ (P-value $\mathrm{p} \leq 0.10)$, which means that if the P-value $p \leq 0.10$, then it can be concluded that within the group of companies (for example, the size of 0-1 employees) there are differences according to the phenomenon that is the subject of the analysis (for example, the use of a fixed telephone for business purposes).

For the purposes of hypothesis testing, derived variables were prepared in advance. A company can develop certain business solutions on their own. For the purposes of the task, a variable was compiled that indicates the use of a business solution in the form of a lease, such as a cloud service (outsourcing). This means that the company does not develop its own solution, but hires it from a specialized provider in the market, including a TC operator. 
Hypothesis 2: The potential of using business solutions to support business, dictated by digital transformation, in the SOHO segment is high.

The relevance of the area of supply, which goes beyond infrastructure services, represents the key guidelines for the development of the business of $\mathrm{TC}$ operators. In the past, the basic principle was that every company must have a fixed telephone number, which is also published in business directories as well as in publicly available sources (for companies that do business with end users). The current level of use of business solutions within SOHO indicates a market opportunity.

The hypothesis was tested on the basis of quantitative research data, which will analyse the share of companies that use individual business solutions. The potential is represented by all companies that do not use business solutions. The analysis was performed on the basis of descriptive frequency distribution statistics and paired t-tests for two dependent samples, which is a statistical method for determining whether the differences in averages between two pair samples are different from zero or from the desired value. The paired ttest is not based on the assumption of equality of variances of the two samples, nor is it based on the assumption of normality, provided that the distribution is symmetric, unimodal, and continuous.

Hypothesis 3: SOHO companies, which are more holistically supported by the operator (providing additional business solutions in addition to basic infrastructure services to support business operations), achieve a higher level of loyalty.

In the saturated market of infrastructure TCs services, the source of the operator's growth is an increase in market share. The key success factors for TC companies are that by expanding the portfolio to other technological areas, they increase loyalty to modern TC companies. Of course, this is a new world of competition, which is very difficult to compete with development services, but they are competitive with their flexibility. Therefore, customer retention activities are key to them. Loyalty to the operator is defined as a situation when a business customer does not express an intention to change the operator. Loyalty to the operator is a key performance indicator and to this end, the operator must identify key activities to ensure the highest level of loyalty of its customers. It could be assumed that there are two key lines of action: (1) achieving loyalty through customer support and care and (2) retaining customers with additional business solutions that support business, setting up, hosting and managing websites, business mail services with a domain, preparation, setting up and managing an online store, document management system services) dictated by digital transformation.

Logistic regression can be used when you have a dependent categorical variable and one or more independent variables. What has already been done is binary logistic regression - which means that the dependent variable is binary ("loyal", "others"). In normal regression, the dependent variable can take any value. To limit binary logistics to values between 0 and 1 , the independent variables have to be transformed with logit transformation. When a regression is being performed, they predict the logarithm of the "prospects" for an event (that a unit is in class 1). Prospects depend on the probability of an event (prospects $=p /(1-p)$, where $p$ is the probability of an event being in group 1). Thus, the interpretation of the coefficients in logistic regression is slightly different than in conventional regression. The characteristic, similar to normal regression, can be interpreted as being some association between the coefficient and the prospect of the event (that you are in class 1). The number $\mathrm{e}^{\wedge}$ coefficient gives us the ratio of the prospects for this variable between the classes (for the binary independent variable) or how much the outlook changes to increase the variable by 1 (for a numerically independent variable).

\subsection{Analysis}

\subsubsection{Description of data}

The sample framework is represented by companies with 0 to 10 employees. The target group is defined in the segment of micro enterprises and sole proprietors. For the purpose of the study, a micro company with 0 to 10 employees is defined as SOHO. On September 30 ${ }^{\text {th }}, 2021$ there were 228162 companies in Slovenia; more than half of them were micro companies (AJPES, 2021). Among the newly created companies in Slovenia, they were in the vast majority micro companies - $99.8 \%$ (SORS, 2021). In 2020, $23 \%$ of small businesses with up to 10 employees and the self-employed generated revenue by selling products or services, receiving orders or reservations via websites (Zupan, 2021). The sample included different company profiles, also by activity. The structure of the sample reflects relatively well the general picture of companies of this size in Slovenia. 


\subsubsection{Analysis and interpretation of results}

Most respondents (90\%) use mobile services, just under three quarters $(73 \%)$ use fixed internet, and a good half (57\%) use traditional and IP telephony. A relatively low share $(22 \%)$ is using Internet TV in companies, while $2 \%$ of companies do not use any services.

The survey showed that companies in the micro segment use basic TC services, namely $57 \%$ of companies use traditional voice telephony and IP telephony services, $73 \%$ of companies use fixed broadband Internet access and $90 \%$ of all companies use voice mobile telephony and transmission services messages. In the voice mobile telephony segment, all companies have approximately the same share of users and in the case of companies with zero to one employee and in companies with six to ten employees $89 \%$, and in companies with two to five employees $91 \%$. There are major differences between companies of different sizes in the use of fixed telephony, which is used by $89 \%$ of companies with six to ten employees, $72 \%$ of companies with two to five employees, while the smallest $(44 \%)$ is used by companies with zero to one employee. Slightly smaller discrepancies occur between different sizes of companies when using fixed broadband Internet (xDSL, FTTx, cable), which is least used by companies with zero to one employee (66\%), followed by companies with two to five employees $(81 \%)$ and companies with six to ten employees $(89 \%)$.

Given the nature of work, mobile services, which include calls and messages, are mostly used by those companies that perform work in the field $(95 \%)$, in the office $(90 \%)$ and at home $(90 \%)$. Slightly smaller is the share of users $(81 \%)$, where work takes place in a bar or shop. Given the nature of work, most users of broadband fixed internet (xDSL, FTTx, cable) are in the segment of companies that perform their activity in offices $(80 \%)$ or from home $(79 \%)$, followed by companies that perform their activity in the field elsewhere $(66 \%)$ or in an office or shop, where the share of companies using broadband fixed internet reaches $70 \%$. The share of the use of traditional telephony and IP telephony is highest in bars or shops $(69 \%)$, followed by companies that perform their activity in the office $(67 \%)$ or elsewhere $(62 \%)$. The services of traditional and IP telephony are used to the least extent by companies that perform their activity from home $(39 \%)$ or work in the field, where half of them use fixed or fixed telephony services.
The users' shares of services and business solutions offered by TC service providers are decreasing; some services, such as domain registration and website hosting, are more in the domain of specialized companies or providers. The use of additional services, such as mobile internet and calls abroad, is also used in quite a few cases by competing TC service providers (not only the main provider). This means that already in the field of basic activities, companies combine the services of several TC providers at the same time. The analysis of potential market should take into account all users and non-users, as companies may, for economic reasons, decide to abandon solutions from their own development and opt for an outsourcing model.

Loyalty was calculated based on a combination of satisfaction and intention to change the supplier. The largest share of loyal customers comes from the segment of those who work at home - $43 \%$ of them, $32 \%$ loyal customers work in a bar or shop, third most loyal $(29 \%)$ customers are those who working in the field, followed by those working in the office $(22 \%)$, while the lowest share of loyal customers is recorded among those working elsewhere, namely $11 \%$.

\subsection{Hypotheses testing}

\subsubsection{Hypothesis 1 testing}

The vast majority of respondents (98\%) use at least one of the basic services (fixed telephony, mobile telephony and fixed internet), while $2 \%$ of users do not use any of the mentioned services (Table 1).

Table 1 At least one of the basic services: fixed telephony, mobile telephony, fixed internet

\begin{tabular}{l|c|c}
\hline & $\mathrm{fx}$ & share \\
\hline doesn't use & 8 & $2 \%$ \\
\hline use & 409 & $98 \%$ \\
\hline together & 417 & $100 \%$ \\
\hline \multicolumn{2}{|c}{ Source: the author's research }
\end{tabular}

Based on the results in Table 2 and the statistical test, it follows that certain business activities do not require all the services which will therefore never be commissioned. Despite the fact that individual infrastructure services do not achieve full penetration, there are statistical differences depending on the nature of the work. On this basis, the hypothesis that the market is saturated has been confirmed, although it does not achieve a full penetration of the use of all services. 
Table 2 Contingency table by nature of work and type of service use classic IP telephony xDSL, FTTx cable modem talks / messages-RS 8

\begin{tabular}{l|c|c|c}
\hline & classic, & xDSL, \\
& IP telephony & $\begin{array}{c}\text { FTTx, } \\
\text { cable } \\
\text { modem }\end{array}$ & $\begin{array}{c}\text { talks/ } \\
\text { RMS }\end{array}$ \\
\hline other $(n=29)$ & $62 \%$ & $66 \%$ & $79 \%$ \\
\hline on field $(n=129)$ & $50 \%$ & $65 \%$ & $95 \%$ \\
\hline in office $(n=144)$ & $67 \%$ & $80 \%$ & $90 \%$ \\
\hline in bar/shop $(n=54)$ & $69 \%$ & $70 \%$ & $81 \%$ \\
\hline from home $(n=61)$ & $39 \%$ & $79 \%$ & $90 \%$ \\
\hline
\end{tabular}

There is a statistically significant relationship between the nature of work and the use of certain TC services $(F=60.74, p=0.000)$.

\subsubsection{Hypothesis 2 testing}

The greatest potential is represented by business solutions, where the potential together amounts to $50 \%$, in dedicated business solutions the potential amounts to $37 \%$, and in standard business solutions the potential is slightly lower and amounts to $35 \%$. The lowest potential is represented by the basic infrastructure, where the potential is $13 \%$.

In the case of standard business solutions, the greatest potential is represented by the mobile cash register $(15 \%)$, with the use on the market being $8 \%$, the second greatest potential $(13 \%)$ being represented by online security solutions, with $48 \%$ of respondents already using this service, the third greatest potential $(11 \%)$ are solutions for websites where the current use is $45 \%$.

In the field of dedicated solutions, the greatest potential is represented by solutions for mobile service platforms $(22 \%)$, where the service is currently used by $13 \%$ of respondents, the second greatest potential is represented by solutions for mobile POS terminals $(10 \%)$, where $18 \%$ of users use the service. represent SMS / MMS marketing solutions $(9 \%)$, where the service is used by $21 \%$ of respondents.

In the area of ancillary services, all services have about the same potential. Thus, mobile internet on phones and smartphones has a potential of $7 \%$, with a share of use of $68 \%$, a potential of $6 \%$ in conversations and sending messages abroad, with a usage of $51 \%$, a potential for using mobile internet on notebooks, modems and similar mobile devices is $7 \%$ at current use $23 \%$, while the potential to use an additional data SIM is $7 \%$ at current use $18 \%$.

Based on the results from Table 3, it can be seen that there are statistically significant differences in the average level of potential between the basic infrastructure solutions and:

- average level of potential of business solutions together $(\mathrm{t}=-13.535$, sig $=$ $0,00)$,

- average level of potential of standard business solutions $(\mathrm{t}=-8.762$, $\mathrm{sig}=0.00)$,

- average level of potential of dedicated business solutions $(\mathrm{t}=-8.633$, $\mathrm{sig}=0.00)$.

Table 3 Paired t-tests (part one)

\begin{tabular}{c|l|c|c|r|r|r|r}
\hline & & \multicolumn{3}{|c|}{ Paired differences } & & \\
\hline Pair & & mean & SD & std. error mean & \multicolumn{1}{c|}{$t$} & df & Sig. \\
\hline 1 & bas_inf - business_together & -0.36930 & 0.55714 & 0.02728 & -13.536 & 416 & 0,000 \\
\hline 2 & bas_inf - stand_business & -0.22542 & 0.52534 & 0.02573 & -8.762 & 416 & 0,000 \\
\hline 3 & bas_inf - dedic_business & -0.24221 & 0.57290 & 0.02806 & -8.633 & 416 & 0,000 \\
\hline \multicolumn{7}{r}{} \\
\hline
\end{tabular}

It follows from the above that statistically significantly higher potential has different forms of business solutions compared to basic infrastructure services.

There are also statistically significant differences between the average values of the potential for joint business solutions and the potential for standard business solutions $(\mathrm{t}=8.362$, sig $=0.000)$ and between the average values of the potential for joint business solutions and the potential for dedicated business solutions $(\mathrm{t}=$ 7.783 , sig $=0.00$ ). This means that joint business solutions have greater potential than other forms of business solutions (Table 4). 
Faganel et al. The main growth strategies of telecommunication operators in the segment of SOHOs

Table 4 Paired t-tests mean potential level in business solutions (second part)

\begin{tabular}{|c|c|c|c|c|c|c|c|}
\hline \multirow[b]{2}{*}{ Pair } & & \multicolumn{3}{|c|}{ Paired differences } & \multirow[b]{2}{*}{$\mathrm{t}$} & \multirow[b]{2}{*}{$\mathrm{df}$} & \multirow[b]{2}{*}{ Sig. } \\
\hline & & mean & SD & std. error mean & & & \\
\hline 1 & business together - stand_business & 0,14388 & 0,35139 & 0,01721 & 8,362 & 416 & 0,000 \\
\hline 2 & business together - dedicat_business & 0,12710 & 0,33348 & 0,01633 & 7,783 & 416 & 0,000 \\
\hline 3 & business together - dedicat_business & $-0,01679$ & 0,52091 & 0,02551 & $-0,658$ & 416 & 0,511 \\
\hline
\end{tabular}

Source: the author's research

Based on this data, the second hypothesis, which says that the potential of business solutions to support business, dictated by digital transformation, is high in the SOHO segment can be confirmed. Thus, there exists a high share of potential customers in the segment of business solutions compared to infrastructure, where there is practically no potential.

\subsubsection{Hypothesis 3 testing}

In the basic services segment, a lower share of loyalty $(25 \%)$ has been recorded in companies that use three or more services than in companies that use one or two services, where the share of loyal companies is $32 \%$. In the standard business solutions segment, the lowest share of loyal companies $(26 \%)$ is recorded in companies that use three or more services, while the share of loyalty is slightly higher for users of one or two standard business solutions and amounts to $31 \%$. For dedicated business solutions, the loyalty rate of companies that use one or two services is $30 \%$, and for those that use three or more services, $28 \%$. In the area of additional services, it is also seen a similar trend as in the other segments already mentioned, with $27 \%$ of companies using three or more services being loyal, while the share of loyalty is slightly higher among companies using one or two services, and is $31 \%$.

There are about 2.56 times more unfaithful companies in the main services segment than loyal ones. The ratio between loyal and unfaithful users of mobile services tends in favour of unfaithful users, who are about 1.26 times more than loyal users. A higher rate of unfaithful companies has been recorded among users of fixed services compared to users of mobile services. Thus, in the case of users of fixed TC services, there are about 1.81 times more unfaithful companies than loyal companies.
In the segment of basic services, the largest share $(54 \%)$ is represented by companies that use one or two services, $44 \%$ of companies use three or more basic services, while the share of companies that do not use any service is negligible and amounts to $2 \%$ ). Just under two thirds of companies $(64 \%)$ do not use standard business solutions, followed by companies $(28 \%)$ that use one or two services, while 8 or more services are used by $8 \%$ of respondents. Also, in the segment of dedicated business solutions, the largest share $(67 \%)$ is represented by companies that do not use the service, followed by companies $(21 \%)$ that use one or two services, while the smallest share (12\%) is represented by companies that use three or more services. There are about 1.6 times more users of basic services who use three basic services than users of basic services who use two services.

Most companies use two additional services ( $\mathrm{n}$ $=74$ ), followed by companies with one additional service $(\mathrm{n}=72)$ and those that use three additional services $(n=63)$. All in all, 52 users do not use additional services. There are the fewest companies that use five additional services - only four companies are such. Most companies do not use any standard business solution $(\mathrm{n}=74)$, followed by users who use one standard business solution $(n=43)$ and users who use two business standard solutions $(n=40)$. Most companies $(n=$ 92) do not use any business solution, followed by companies that use one dedicated business solution $(n=69)$, and in third place $(n=42)$ are companies that use three dedicated business solutions, while the share of companies with a larger number of dedicated business solutions is significantly lower.

In the following, three models of logistic regression have been prepared, where the dependent variables are dichotomous ( 0 - loyal, 1 disloyal) and refer to the users of fixed services, mobile services and main services, which are shown in Table 5. 
Table 5 Presentation of three logistic regression models

\begin{tabular}{l|l|l}
\hline Model & Dependent categorical variable & Independent variables \\
\hline 1 & Loyal_main3 & $\begin{array}{l}\text { Basic_services, additional_services, standard_business, } \\
\text { dedicated_business }\end{array}$ \\
\hline 2 & Loyal_fix3 & $\begin{array}{l}\text { Basic_services, additional_services, standard_business, } \\
\text { dedicated_business }\end{array}$ \\
\hline 3 & Loyal_mob3 & $\begin{array}{l}\text { Basic_services, additional_services, standard_business, } \\
\text { dedicated_business }\end{array}$ \\
\hline
\end{tabular}

Source: the author's research

In the first model, none of the coefficients is statistically significant, so nothing can be concluded about the influence of independent variables in the model on the loyalty of users of main services (Table 6).
In the second model too, no coefficient is statistically significant, so nothing can be concluded about the influence of independent variables in the model on the loyalty of users of fixed services (Table 7)

Table 6 Model 1 (logistic regression - main)

\begin{tabular}{l|c|c|c|c}
\hline \multicolumn{7}{c|}{ Min } & $1 \mathrm{Q}$ & Median & $3 \mathrm{Q}$ & Max \\
\hline \multicolumn{1}{c|}{-1.7767} & -1.4621 & 0.768 & 0.8394 & 0.9839 \\
\hline \multicolumn{5}{|c|}{ Coeff. } \\
\hline Intercept) & Estimate & Std. error & z value & $\operatorname{Pr}(>|z|)$ \\
\hline Basic_services & 0.005332 & 0.693490 & 0.008 & 0.994 \\
\hline Additional_services & 0.338912 & 0.263127 & 1.288 & 0.198 \\
\hline Standard_business & 0.017074 & 0.110011 & 0.155 & 0.877 \\
\hline Dedicated_business & 0.047975 & 0.063493 & 0.756 & 0.450 \\
\hline
\end{tabular}

Source: the author's research

Table 7 Model 2 (logistic regression - fixed services)

\begin{tabular}{l|c|c|c|c}
\hline \multicolumn{7}{c}{ Deviance residuals } \\
\hline \multicolumn{1}{c|}{ Min } & $1 \mathrm{Q}$ & Median & $3 \mathrm{Q}$ & Max \\
\hline \multicolumn{1}{c|}{-1.6247} & -1.3827 & 0.8803 & 0.9521 & 1.153 \\
\hline \multicolumn{7}{c|}{ Coeff. } \\
\hline (Intercept) & Estimate & Std. error & z value & $\operatorname{Pr}(>|\mathrm{z}|)$ \\
\hline Basic_services & 0.21348 & 0.66227 & 0.322 & 0.747 \\
\hline Additional_services & 0.13249 & 0.24917 & 0.532 & 0.595 \\
\hline Standard_business & -0.02050 & 0.10284 & -0.199 & 0.842 \\
\hline Dedicated_business & 0.07959 & 0.05969 & 1.333 & 0.182 \\
\hline
\end{tabular}

The results in Table 8 indicate that there is a statistically significant impact of basic services (Wald z-statistics $=2.203, \mathrm{p}=0.0276$ ) on the loyalty of mobile service users, where the coefficient for basic services is 0.533 , which means that the outlook will be that the company will become unfaithful will increase by about $70 \%$ if the number of basic services would be increased by one unit.
There is a conditionally statistically significant influence of standard business solutions (Wald zstatistics $=1.721, p=0.0852$ ) on the loyalty of mobile service users, where the coefficient for standard business services is 0.0997 , which means that the company becomes unfaithful, increased by $10.4 \%$ under other unchanged conditions, if the number of standard business solutions is increased by one unit (Table 8 ). 
Table 8 Model 3 (logistic regression - mobile services)

\begin{tabular}{l|c|c|c|c}
\hline \multicolumn{7}{c}{ Deviance residuals } \\
\hline \multicolumn{1}{c|}{ Min } & $1 \mathrm{Q}$ & Median & $3 Q$ & Max \\
\hline \multicolumn{7}{c|}{-1.5433} & -1.2424 & 0.8956 & 1.0596 & 1.4418 \\
\hline \multicolumn{5}{|c|}{ Coeff. } \\
\hline \multicolumn{7}{|c|}{ Estimate } & Std. error & z value & $\operatorname{Pr}(>|\mathrm{z}|)$ \\
\hline (Intercept) & -1.285620 & 0.644087 & -1.996 & $0.0459^{*}$ \\
\hline Basic_services & 0.533515 & 0.242190 & 2.203 & $0.0276^{*}$ \\
\hline Additional_services & -0.007450 & 0.099910 & -0.075 & 0.9406 \\
\hline Standard_business & 0.099767 & 0.057955 & 1.721 & 0.0852 \\
\hline Dedicated_business & -0.120670 & 0.089591 & -1.347 & 0.1780 \\
\hline
\end{tabular}

The third hypothesis is rejected, as more comprehensive support for standard business solutions and basic services does not mean greater loyalty of mobile service users. A statistically significant effect of integrated support on the loyalty of users of fixed and main services has not been registered.

\section{Conclusion}

The traditional sources of income for TC operators, based predominantly on subscriptions and metered services, became obsolete. This study has found that digital transformation cuts deep into the business as well as the private daily routine. It has been acknowledged that telecom operators face a major turning point - to remain a traditional TC operator that will provide SOHO companies with basic infrastructure services that can be said to be saturated in the market, or cross the digitalization threshold, i.e. remain a "donor" of physical infrastructure to OTT providers or take a step forward and try to monetize content flowing through valuable lines.

The latter may be the subject of further research and controversy, but the real fact is that the SOHO segment of companies represents the potential for long-term and stable growth of TC operators. This fact has been confirmed with the present research. The main challenges that SOHO companies have in their business have been listed, namely revenue and productivity growth, cost reduction, more efficient sales to their customers, efficient transfer of knowledge and information between employees, a single database accessible from anywhere and anytime via any device. The research confirmed that there is potential for business solutions in the SOHO companies' market, with which TC operators would be able to meet the previously mentioned challenges of companies. In this way, operators can create a partnership in terms of mutual development and creating growth for all stakeholders in the process.

Furthermore, based on the research, it has been proved that loyalty in the $\mathrm{SOHO}$ segment of companies is not related to the number of services and business solutions that the company uses. Based on literature, it can be assumed that company loyalty is the basis for creating potential through additional services and business solutions and represents the first phase in a relatively long purchase process of business solutions.

It has been demonstrated in the paper that the market in the segment of SOHO companies on basic infrastructure TC services is saturated; there is potential for operators to offer additional services and business solutions, and the loyalty of companies is not related to the amount of implemented business solutions. The main growth guidelines represent a great opportunity for operators and stem from the challenges of $\mathrm{SOHO}$ companies to cross the threshold and enter the process of digital transformation. Therefore, operators need to be prepared - the main growth guidelines are conditioned by adjusting their strategic goals, redefining business processes, upgrading technology, raising the level of relations with companies and establishing a partner ecosystem.

Based on the literature review and study findings, it can be said that there are many different strategic options for TC operators to choose in their field, but the main growth strategy of digital TC operators to recommend in the segment of SOHOs would be to concentrate on establishing a close relationship and develop partnership with their customers, in order to analyse their needs, and provide services and know how, that would allow the multiple rewarding and satisfying growth of all 
the involved stakeholders. TC operators should seize the opportunities within the detected high share of potential customers in the segment of business solutions. To be able to confront this transformation, they have to adjust their strategies and strategic goals, redefine their business processes, upgrade the technology, raise the level of business relationship and develop a partner ecosystem. This would allow SOHO companies to concentrate on their core business process and competences, with a strong support from their selected TC operator.

The findings of this article could be useful for TC researchers dealing with transformational projects, institutional investors for establishing and evaluating their development plans and decisions, and TC management consultants, providing them with a basis for their clients' transformation engagement. And, in forefront, there are study results very important for TC operators' leaders and managers.

Limitations of this study are related to the analysis of the companies' activities. The sample of 417 companies is still too small to be able to analyse companies according to the standardized classification activity codes and thus identify differences by very specific industry sectors. For this purpose, segmentation of activities according to the nature of work was used, which to a certain extent indicates differences in the activity of companies and thus the relevance of individual services. Another limitation is the one country case study, which could be subject to specific circumstances in the business environment, which could vary from country to country.

Future business will show how well companies, organizations and government agencies use technology to collaborate with partners and customers through a wide range of digitized processes. However, digital transformation is neither simple nor unambiguous. From the point of view of the organizational market users, despite global trends, there is still a large gap in the exploitation of technologies. While exploring new technological possibilities, organizations need to face the need to change. Organizational and cultural changes and shifts in the nature of their business will pose the most difficult challenges in the future.

The importance of this study is in the fact that only a few similar research studies have been found in the literature review. Other researchers could make use of this study as a conceptual blueprint to start their own investigations in other countries' settings. As the technology is also evolving extremely fast in this area, it is necessary to follow this progress and offer research results that will be up-to-date, so no study is definitive and absolute.sm

\section{References}

Agencija za komunikacijska omrežja in storitve Republike Slovenije [AKOS]. (2021). Operaterji. Retrieved November 25, 2021, from https://www.akosrs.si/registri/seznam-registrov/operaterji

AJPES. (2021). Poslovni subjekti v poslovnem registru Slovenije po skupinah, po četrtletjih.

https://www.ajpes.si/Doc/Registri/PRS/Porocila/posl_su bj_skup_30092021.pdf AKOS. (2021). Operaterji. Retrieved November 25, 2021, from https://www.akosrs.si/registri/seznam-registrov/operaterii

Arthur D. Little. (2018). Telecoms data monetization: Reality, not a mirage. Retrieved November 27, 2021, from, https://www.adlittle.com/en/insights/report/telecomsdata-monetization-reality-not-mirage

Bailey, H. (2015). ICT services for SMEs: worldwide trends and forecasts 2015-2020. Retrieved November 25, 2021, from http://www.analysysmason.com/Research/Content/Rep orts/SME-ICT-forecasts-Dec2015RDMZ0/\#22\%20December\%202015 (12. 11. 2021).

Bouwman, H., Nikou, S., \& de Reuvera, M. (2019). Digitalization, business models, and SMEs: How do business model innovation practices improve performance of digitalizing SMEs? Telecommunications Policy, 43(9), 101828. https://doi.org/10.1016/j.telpol.2019.101828

Chen, C.-M. (2019). Evaluating the efficiency change and productivity progress of the top global telecom operators since OTT's prevalence. Telecommunications Policy, 43(7), 1-24. https://doi.org/10.1016/j.telpol.2019.01.004

Curwen, P., \& Whalley, J. (2004). Telecommunications Strategy Cases, Theory and Applications. Abingdon: Routledge. https://doi.org/10.4324/9780203481608

Dasanayaka, S.W.S.B., Al Serhan, O., Glambosky, M., \& Gleason, K. (2020). The business-to-business relationship: examining Sri Lankan telecommunication operators and vendors. Journal of Business \& Industrial Marketing, 35(6), 1069-1087. https://doi.org/10.1108/JBIM-06-2019-0303

Dutta, G., Kumar, R., Sindhwani, R. \& Singh, R.K. (2020). Digital transformation priorities of India's discrete manufacturing SMEs - a conceptual study in perspective of Industry 4.0, Competitiveness Review 30(3), 289-314. https://doi.org/10.1108/CR-03-2019-0031

etno (European telecommunications network operators association). (2021). The state of digital communications. Retrieved November 28, 2021, from https://etno.eu/library/reports/95-state-of-digi-2021.html

Fabre, S., \& Skorupa, J. (2020). Tech Providers 2025: Future of Telecommunications Infrastructure Vendors Ecosystem Landscape. Stamford: Gartner Inc. 
Faganel, A., \& Costantini, M. (2020). CRM adoption factors in the gaming industry. Management: journal of contemporary management issues 25(1), 1-23. https://doi.org/10.30924/mjcmi.25.1.1

Farooq, M., \& Raju, V. (2019). Impact of over-the-top (OTT) services on the telecom companies in the era of transformative marketing. Global Journal of Flexible Systems Management, 20, 177-188. https://doi.org/10.1007/s40171-019-00209-6

Ganuza, J. J., \& Viecens, M. F. (2014). Over-the-top (OTT) content: implications and best response strategies of traditional telecom operators. Evidence from Latin America. info, 16(5), 59 - 69. http://dx.doi.org/10.1108/info-05-2014-0022

Garcia, V. (2021). Examining the Impact of selling on amazon on the revenue growth of MSEs in the US. International Journal of Contemporary Financial Issues 1(1), 28-38.

https://doi.org/10.17613/75cc-7022

Garzoni, A., De Turi, I., Secundo, G., \& Del Vecchio, P. (2020). Fostering digital transformation of SMEs: a four levels approach. Management Decision 58(8), 15431562.

https://doi.org/10.1108/MD-07-2019-0939

Gošnik, D., \& Stubelj, I. (2021). Business process management and risk-adjusted performance in SMEs", Kybernetes, (ahead-of-print). https://doi.org/10.1108/K-11-2020-0794

Hushyar, K., Braun, H., \& Eslambolchi, H. (2021). Telecom Extreme Transformation The Road to a Digital Service Provider. Abingdon: Routledge. https://doi.org/10.1201/9781003160748

Janeš, A., Biloslavo, R., \& Faganel, A. (2017). Sustainable business model: a case study of Fonda.si. Annales: anali za istrske in mediteranske študije. Series historia et sociologia 27(1), 175-190. https://doi.org/10.19233/ASHS.2017.14

Kääriäinen, J., Pussinen, P., Saari, L., Kuusisto, O., Saarela, M., \& Hänninen, K. (2021). Applying the positioning phase of the digital transformation model in practice for SMEs: toward systematic development of digitalization. International journal of information systems and project management 8(4), 24-43. https://doi.org/10.12821/ijispm080402

Katz, R., Jung, J., \& Callorda, F. (2020). Can digitization mitigate the economic damage of a pandemic? Evidence from SARS. Telecommunications Policy 44(10), 102044. https://doi.org/10.1016/j.telpol.2020.102044

Kim, S.-S. (2021). Sustainable growth variables by industry sectors and their influence on changes in business models of SMEs in the Era of digital transformation. Sustainability, 13(13), 7114. https://doi.org/10.3390/su13137114

Klein, V. B., \& Todesco, J. L. (2021). COVID-19 crisis and SMEs responses: The role of digitaltransformation. Knowledge and processes management, 28(2), 117133. https://doi.org/10.1002/kpm.1660

Krüssel, P., \& Göbel, F. (2019). Successful Positioning of Network Operators in the Digital Age. In P. Krüssel (Ed.), Future Telco (pp. 1-24). Cham: Springer. https://doi.org/10.1007/978-3-319-77724-5 1
Matarazzo, M., Penco, L., Profumo, G., \& Quaglia, R. (2021). Digital transformation and customer value creation in Made in Italy SMEs: A dynamic capabilities perspective. Journal of Business Research, 123(2), 642-656.

https://doi.org/10.1016/j.jbusres.2020.10.033

Mouelhi, R. B. A., \& Ghazali, M. (2021). Growth of micro, small and medium enterprises (MSMEs) in MENA countries: constraints and success factors. Sustainable Business and Society in Emerging Economies, 3(2), 5973. https://doi.org/10.26710/sbsee.v3i1.1643

Mandviwalla, M., \& Flanagan, R. (2021). Small business digital transformation in the context of the pandemic. European Journal of Information Systems, 30(4), 359375. https://doi.org/10.1080/0960085X.2021.1891004

Novak, R., \& Janeš, A. (2019). Business process orientation in the Slovenian power supply. Business process management journal, 25(4), 780-798. https://doi.org/10.1108/BPMJ-05-2017-0130

Papadopoulos, T., Baltas, K. N., \& Balta, M. E. (2020). The use of digital technologies by small and medium enterprises during COVID-19: Implications for theory and practice. International Journal of Information Management 55, 102192. https://doi.org/10.1016/j.ijinfomgt.2020.102192

Pelletier, C., \& Cloutier, L.M. (2019). Conceptualising digital transformation in SMEs: an ecosystemic perspective. Journal of Small Business and Enterprise Development, 26(6/7), 855-876. https://doi.org/10.1108/JSBED-05-2019-0144

Peter, M.K., Kraft, C., \& Lindeque, J. (2020). Strategic action fields of digital transformation: an exploration of the strategic action fields of Swiss SMEs and large enterprises. Journal of Strategy and Management, 13(1), 160-180. https://doi.org/10.1108/JSMA-05-2019-0070

Priyono, A., Moin, A., \& Putri, V. N. A. O. (2020). Identifying digital transformation paths in the business model of SMEs during the COVID-19 pandemic. Journal of Open Innovation: Technology, Market, and Complexity, 6(4), 104. https://doi.org/10.3390/joitmc6040104

Ramnath Babu, C. N. S., \& Sivanesan, G. (2020). A comparative study of factors influencing the choice decision of mobile network operators between large and, small and medium enterprise (SME) customers. Seventeenth AIMS International Conference on Management, 1116-1126.

Rand, J., \& Tarp, F. (2020). Micro, Small, and Medium Enterprises in Vietnam. Oxford: Oxford University Press. https://doi.org/10.1093/oso/9780198851189.001.0001

Sahoo, B. B., \& Swain, K. C. (2020). Micro, small and medium enterprises (msmes) in India: The engine of growth. International journal of social sciences, 9(1), 3143. https://doi.org/10.30954/2249-6637.01.2020.5

Simonite, T. (2015). Billions of people could get online for the first time thanks to helium balloons that Google will soon send over many places cell towers don't reach. Retrieved November 25, 2021, from https://www.technologyreview.com/s/534986/projectloon/ (13. 11. 2021). 
SORS. (2021). Enterprises by activities (NACE Rev. 2) and size class by number of persons employed, Slovenia, annually. Retrieved November 21, 2021, from https://pxweb.stat.si/SiStatData/pxweb/en/Data/|1418801S.px|

Sridhar, V. (2019). Emerging ICT Policies and Regulations: Roadmap to Digital Economies. Singapore: Springer Nature.

https://doi.org/10.1007/978-981-32-9022-8

Sujata, J., Sohag, S., Tanu, D., Chintan, D., Shubham, P., \& Sumit, G. (2015). Impact of Over-the-Top (OTT) services on telecom service providers. Indian Journal of Science and Technology, 8(S4), 145-160. https://doi.org/10.17485/ijst/2015/v8iS4/62238

Tarvainen, T. (2020). Strategies of European Telecom Operators in Challenging Environment (Master's thesis). Available from https://www.theseus.fi/bitstream/handle/10024/352196/ Tarvainen Tatu.pdf?sequence $=6$

Telekom Slovenia. (2021). Annual report for 2020. Telekom Slovenije, d. d., Ljubljana, Slovenia. Retrieved November 22, 2021, from https://www.telekom.si/Documents/Annual-report2020.pdf

\section{$\square$ Correspondence}

\section{Armand Faganel}

University of Primorska

Izolska vrata 2, 6000 Koper, Slovenia

E-mail: armand.faganel@fm-kp.si
Vrana J., \& Singh R. (2021). Digitization, digitalization, and digital transformation. In Meyendorf N., Ida N., Singh R., Vrana J. (Eds.), Handbook of Nondestructive Evaluation 4.0 (pp. 1-17). Cham: Springer. https://doi.org/10.1007/978-3-030-48200-8 39-1

Zupan, G. (2021). V 2020 ustvarila prihodek s spletno prodajo skoraj četrtina podjetij $z$ vsaj 10 zaposlenimi in samozaposlenimi. Retrieved November 22, 2021, from https://www.stat.si/StatWeb/News/Index/9890

Wang, H. T. (2021). Discussion of the competitive strategies of telecom operators and Over-the-Top service providers from the perspective of evolutionary game theory. Decision analysis, 17(3), 187-275. https://doi.org/10.1287/deca.2019.0407

Wiersma, H., \& Nijboer, F. (2021). Telecoms outlook 2021 The need for speed. Retrieved November 26, 2021, from https://think.ing.com/uploads/reports/ING Telecom Out look January 2021.pdf 